\title{
The effect of alpha blockers on uroflowmetric parameters in different voiding positions
}

\author{
Gokhan Koc, MD; Yuksel Yilmaz, MD; Sitki Un, MD; Kaan Akbay, MD; Firat Akdeniz, MD \\ Tepecik Teaching and Research Hospital Urology Department, Yenisehir, Izmir, Turkey
}

Cite as: Can Urol Assoc J 2013;7(5-6):329-32. http://dx.doi.org/10.5489/cuaj.12091

Published online May 13, 2013 (early released November 14, 2012).

\section{Abstract}

Introduction: We assessed the effect of different voiding positions on uroflowmetric parameters and post-void residual (PVR) urine volume in symptomatic benign prostatic hyperplasia (BPH) patients. We also evaluated the effect of alpha blockers on PVR in different voiding positions.

Methods: The study was performed with $110 \mathrm{BPH}$ patients over 50 years old. In total, 4 uroflowmetries were performed in all patients: 2 patients in the sitting position and 2 in the standing position. PVR was measured with transabdominal ultrasonography. Also, patients were divided into two groups according to the alpha adrenergic blocker treatment; the effect of this treatment on their uroflowmetric parameters in different positions was evaluated.

Results: Maximum flow rate (Qmax) and average flow rate (Qave) were significantly higher in patients in the sitting position, but there were no differences in other uroflowmetric parameters and PVR volume (Qmax: $15.5 \pm 5.9 \mathrm{~mL} / \mathrm{s}$ vs. $13.7 \pm 5.2 \mathrm{~mL} / \mathrm{s}$, Qave: $11.4 \pm 4.6 \mathrm{~mL} / \mathrm{s}$ vs. $10.7 \pm 3.9 \mathrm{~mL} / \mathrm{s}$, respectively; $p<0.05)$. The Qmax and Qave were significantly higher in sitting position, compared to the standing position, in both alpha adrenergic treatment and non-treated groups; again, there were no differences in other uroflowmetric parameters and PVR volume.

Conclusion: Qmax and Qave values were significantly higher in the sitting position. Alpha blockers did not affect any change.

\section{Introduction}

Uroflowmetry is a cost-effective and simple way to perform non-invasive tests for patients with lower urinary tract symptoms (LUTS). ${ }^{1}$ It is also recommened for patients undergoing surgery for bladder outlet obstruction due to benign prostatic hyperplasia $(\mathrm{BPH}) .^{2}$

Uroflowmetric parameters can be affected by various factors, such as age, gender and voiding volume (VV). ${ }^{3-5}$ Urinary flow rate also has a circadian rhythm. ${ }^{6}$

Voiding positions are different according to social, cultural and medical norms. Most men in western countries void while standing, but in some Asian and Middle Eastern countries prefer to void in the sitting or squatting position. It is important to empty the bladder totally because high post-voiding residual urine (PVR) can lead to urinary tract infections and bladder stone disease. The best position for emptying the bladder is controversial and not yet established. ${ }^{7-19}$

There are no studies which assess the effects of alpha blockers on PVR volumes in different voiding positions. We evaluated the effect of the sitting and standing voiding positions on uroflowmetric parameters and PVR in patients over 50 years old and with LUTS due to BPH. We also assessed the effect of alpha blockers on the PVR volumes in these different voiding positions.

\section{Methods}

We studied 110 men over 50 years old. Written informed consent was obtained for each patient and approval was obtained from the local Ethics Committee. Patients receiving alpha adrenergic blockers were also included, and subgroups were formed according to this treatment. Group 1 included 44 (taking treatment) and group 2 include 66 (not taking treatment) patients. The mean duration of alpha adrenergic blockers in the drug-treated group was 37.6 \pm 38.6 weeks. No patients were on combination therapy and all were pleased with their drugs. Detailed history was taken from all patients and LUTS was evaluated with International Prostate Symptom Score (IPSS). We performed physical examinations with digital rectal examination (DRE), whole urine analysis, some laboratory analysis, including prostate spesific antigen (PSA) and transabdominal urinary system ultrasonography (LOGIQ C2, GE Medical Systems, USA). Prostate volumes were also recorded during ultrasonography.

We excluded patients with a history of prostate surgery, urethral stricture, neurologic disease and diabetes mellitus. We also excluded patients with a urinary tract infection, bladder stones, PSA values over $4 \mathrm{mg} / \mathrm{mL}$, suspicious nodule demonstrated by DRE and prostate cancer. We performed 
Koc et al.

uroflowmetry using a weight transducer urodynamic device (Solar Urodynamic System, Medical Measurement System, USA). Uroflowmetric measurements were performed in a private room locked from the inside and out of the hearing range of other staff members. In total, 4 uroflowmetries were done; 2 patients in the standing position and the other 2 in the sitting position. In half of the group, measurements were done in the sitting position followed by the standing position; in the other half, first in the standing followed by the sitting position. Each test was repeated twice and four measurements were taken for each patient (for a total of 440 measurements). The circadian rhythm was taken into account; one measurement was taken in the morning and the other in the afternoon for each position. To prevent patient exhaustion, measurements were completed in two days. If a patient's voiding volume was under $150 \mathrm{cc}$, the procedure was repeated and PVR was measured using transabdominal ultrasound.

Statistical analyses were done using SPSS 16. Paired t-tests and Mann-Whitney $U$ tests were done for parametric and nonparametric comparisons, respectively; $p<0.05$ was considered significant.

\section{Results}

Baseline characteristics, except IPSS, were similar between the two groups (Table 1). A comparison of the uroflowmetric parameters showed that maximum flow rate (Qmax) and the average flow rate (Qave) were statistically higher in the sitting group; there were no differences between the urine volume, residual volume and voiding time parameters (Table 2). Within Group 1, the Qmax and Qave were significantly higher than in Group 2; there were no differences in the other parameters (Table 3). In Group 2, the Qmax and Qave were significantly higher in patients in the sitting position; also in this group, there were no statistical differences in the other parametres (Table 4).

\section{Discussion}

There are a number of studies examining the effects of different voiding positions on uroflowmetric parameters.

Unsal and colleagues studied healthy men and compared their uroflowmetric parameters and PVR in different posi-

\begin{tabular}{lccc}
\hline \multicolumn{4}{c}{ Table 1. Baseline characteristics of Group 1 and Group 2 } \\
\hline & Group 1 & Group 2 & $\boldsymbol{p}^{*}$ \\
\hline Age & $62.4 \pm 5.3$ & $60.5 \pm 5.9$ & 0.09 \\
PSA (ng/mL) & $2.0 \pm 1.0$ & $1.8 \pm 0.8$ & 0.38 \\
IPSS & $14.9 \pm 3.9$ & $10.4 \pm 4.1$ & $<0.05$ \\
Prostate volume (mL) & $49.3 \pm 21.4$ & $47.2 \pm 20.9$ & 0.60 \\
\hline *according to test. PSA: prostate-specific antigen; IPSS: International Prostate Symptom \\
\multicolumn{4}{l}{ Score. }
\end{tabular}

tions: standing, sitting and crouching. They authors reported that these different positions do not have an effect on uroflowmetric parameters and PVR. ${ }^{7}$ The authors also compared the uroflowmetric parameters and the PVR volume in healthy women in sitting and crouching positions; similarly, they could not find a significant difference between the positions. ${ }^{7}$ Riehmann and colleagues reported that standing is better than the recumbent position. ${ }^{8}$ Yamanishi and colleagues compared uroflowmetry in standing, sitting, lateral, supine, prone positions in men between the ages of 24 and 40; they found the highest Qmax rate with the prone position. The Qmax rate decreased in the standing, sitting, supine and lateral positions. ${ }^{9}$ Eryıldırım and colleagues found that Qmax and Qave values were significantly higher in the sitting and squatting positions. ${ }^{10}$ Conversely, Choudry and colleagues found that Qmax and Qave values were significantly lower in sitting position. ${ }^{11}$

There are studies with healthy women. Devreese and colleagues evaluated uroflowmetric parameters and could not find a statistical difference between the positions. ${ }^{12}$ Gupta and colleagues found that Qmax and Qave values were significantly lower in the sitting position. ${ }^{13}$ Moore and colleagues reported that Qmax and Qave values were significantly higher and PVR was significantly lower in the sitting position. ${ }^{14}$ In a recent study of 21 women with osteoartritis, Chou and colleagues found no difference between the sitting and standing positions in terms of Qmax, Qave, VV and PVR. ${ }^{15}$

Unsal and colleagues compared the sitting and standing positions in 44 symptomatic BPH patients and 44 agematched healthy men; they did not find a significant difference in the uroflowmetric parameters in these two positions - this is similar to our study. ${ }^{16}$ Moreover, Aghamir and colleagues compared the different positions in 10 symptomatic $\mathrm{BPH}$ patients and 10 age-matched healthy men. The authors did not find a difference in the positions in the healthy group, but in $\mathrm{BPH}$ group the PVR was lower in the sitting position. ${ }^{17}$ Amadi and colleagues studied 83 symptomatic BPH patients and reported that Qmax values were significantly higher and PVR values were significantly lower in the crouching position. ${ }^{18} \mathrm{El}$-Bahnasawy and colleagues reported that when patients were substratified according to age (50 years and less, and over 50 years), Qmax values were significantly higher in the sitting position than in the standing position

\begin{tabular}{lccc}
\hline \multicolumn{4}{c}{ Table 2. Uroflowmetric parameters of the study groups } \\
\hline & Sitting & Standing & $\boldsymbol{p}^{*}$ \\
\hline Omax $(\mathrm{mL} / \mathrm{s})$ & $15.5 \pm 5.9$ & $13.7 \pm 5.2$ & $<0.05$ \\
Qave $(\mathrm{mL} / \mathrm{s})$ & $11.4 \pm 4.6$ & $10.7 \pm 3.9$ & $<0.05$ \\
Urine volume $(\mathrm{mL})$ & $334.7 \pm 121.4$ & $317.0 \pm 111.9$ & 0.15 \\
Residual volume $(\mathrm{mL})$ & $103.7 \pm 83.9$ & $107.1 \pm 79.8$ & 0.5 \\
Voiding time (sec) & $51.5 \pm 25.1$ & $54.0 \pm 26.3$ & 0.19 \\
\hline *according to test. Omax: maximum flow rate; Qave: average flow rate.
\end{tabular}




\begin{tabular}{lccc}
\hline \multicolumn{4}{l}{ Table 3. Uroflowmetric parameters of Group 1 } \\
\hline & Sitting & Standing & $\boldsymbol{p}^{*}$ \\
\hline Omax $(\mathrm{mL} / \mathrm{s})$ & $15.7 \pm 5.4$ & $14.0 \pm 4.5$ & $<0.05$ \\
Qave $(\mathrm{mL} / \mathrm{s})$ & $11.6 \pm 4.2$ & $10.8 \pm 3.5$ & $<0.05$ \\
Urine volume $(\mathrm{mL})$ & $344.1 \pm 130.6$ & $321.7 \pm 122.4$ & 0.17 \\
Residual volume $(\mathrm{mL})$ & $96.8 \pm 65.8$ & $104.6 \pm 62.0$ & 0.24 \\
Voiding time (sec) & $42.2 \pm 22.4$ & $42.8 \pm 23.4$ & 0.67 \\
\hline *according to test. Omax: maximum flow rate; Qave: average flow rate.
\end{tabular}

in the under 50 group but not in over 50 group.${ }^{19}$ Our study included symptomatic BPH patients over 50 years of age. We found that Qmax and Qave values were significantly higher in the sitting group when compared with the standing position; other parameters were not affected by the different positions. When patients were divided into subgroups due to alpha adrenergic blocker treatment, Qmax and Qave values were significantly higher in the sitting position and other parameters did not show any statistically significant difference. In the non-treated group, Qmax and Qave values were significantly higher in the sitting position, with no statistical difference in other parameters.

Our study group experienced frequent voiding problems. The uroflowmetric parametres in patients taking alpha adrenergic blockers have never been evaluated. Therefore, we evaluated the effects of alpha adrenergic blocker treatment on uroflowmetric parameters in different voiding positions. This is the first study evaluating this effect. In our study, Groups 1 and 2 (patients receiving alpha adrenergic blocker or not) had similar results. The alpha blockers did not affect uroflowmetric parametres in different voiding positions.

Better flow values with the sitting position are generally due to two mechanisms. First, higher pressure transmission on the urinary bladder is due to increased intra-abdominal pressure in the sitting position; second, pelvic floor muscles are more relaxed during the sitting position, which leads to an increased flow rate. ${ }^{10,18}$ Also patient comfort, psychology and preferred voiding position affect the maximum flow rate. If an individual is accustomed to voiding in a certain position, changing it can cause stress and discomfort - these can affect uroflowmetric parameters. In our study, $69 \%$ of patients preferred the sitting position and $31 \%$ the standing position. Our results were affected by the following factors: patients in the sitting position experienced easier transmission of urine due to increased intra-abdominal pressure and relaxed pelvic floor muscles; the stress and discomfort of these patients in the standing position affected their uroflowmetric parameters. Ideally intraabdominal pressure measurements by transrectal pressure sensors and electromyography recording should be performed to clearly define the effects of positional differences.

Qmax and Qave values were statistically significantly high in both groups, while clinically no significant difference was detected. This difference did not appear in the clinical

\begin{tabular}{lccc}
\hline \multicolumn{4}{l}{ Table 4. Uroflowmetric parameters of Group 2} \\
\hline & Sitting & Standing & $\boldsymbol{p}^{*}$ \\
\hline Omax $(\mathrm{mL} / \mathrm{s})$ & $15.4 \pm 6.3$ & $13.5 \pm 5.6$ & $<0.05$ \\
Qave $(\mathrm{mL} / \mathrm{s})$ & $11.3 \pm 4.9$ & $10.6 \pm 4.2$ & $<0.05$ \\
Urine volume $(\mathrm{mL})$ & $320.7 \pm 93.8$ & $310.0 \pm 94.9$ & 0.58 \\
Residual volume $(\mathrm{mL})$ & $110.9 \pm 97.8$ & $114.8 \pm 109.0$ & 0.71 \\
Voiding time $(\mathrm{sec})$ & $57.4 \pm 26.0$ & $61.9 \pm 24.8$ & 0.12 \\
\hline *according to test. Omax: maximum flow rate; Qave: average flow rate. &
\end{tabular}

data, such as urine volume, residual volume and voiding time. Therefore, considering this negligible difference, men would likely continue in their habitual and preferred voiding position.

When performing uroflowmetry, voiding in a different position would result in unnecessary stress, therefore, various positional options should be given to the patient during uroflowmetry. Additionally, to avoid inconsistencies from different voiding positions during uroflowmetry, we suggest that patients are in the same position every time to perform uroflowmetry.

\section{Conclusions}

Positional differences affected uroflowmetric parameters. Voiding flow rates in the sitting position were significantly better than in the standing position for symptomatic BPH patients; alpha adrenergic blockers did not eliminate affect the rates between the two positions. Moreover, the PVR values were lower in the sitting position with alpha adrenergic blocker treatment. Although rate may be higher during uroflowmetric evaluation in the sitting position, personal preferences must be taken into account because patient comfort during voiding will affect the flow rates.

Competing interests: None declared.

This paper has been peer-reviewed

\section{References}

1. Grino PB, Bruskewitz R, Blaivas JG, et al. Maximum urinary flow rate by uroflowmetry: automatic or visual interpretation. J Urol 1993; 149:339-41.

2. Madersbacher S, Alivizatos G, Nordling J, et al. EAU 2004 guidelines on assessment, therapy and follow-up of men with lower urinary tract symptoms suggestive of benign prostatic obstruction (BPH guidelines). Eur Urol 2004; 46:547-54.

3. Jensen KM-E, Jorgensen JB, Morgensen P. Reproducibility of uroflowmetric variables in elderly males. Urol Res 1985; 13:237-9.

4. Jorgensen JB, Jensen KM, Mogensen P. Age-related variation in urinary flow variables and flow curve patterns in elderlymales. Br I Urol 1992;69:265-71.

5. Karl C, Gerlach R, Hannapel J, et al. Uroflow measurements: Their information yield in a long term investigation of pre and post operative measurements. Urol Int 1986;41:270-5.

6. Witjes WP, Wijkstra $H$, Debruyne FM, et al. Quantitative assessment of uroflow: Is here a circadian rhythm? Urology 1997;50:221-8. 
Koc et al.

7. Unsal A, Cimentepe E. Voiding position does not affect uroflowmetric parameters and post void residual urine volume in healthy volunteers. Scand J Urol Nephrol 2004;38:469-71.

8. Riehmann M, Bayer WH, Drinka PJ, et al. Position related changes in voiding dynamics in men. Urology 1998:52:625-30.

9. Yamanishi T, Yasuda K, Sakakibara R, et al. Variation in urinary flow according to voiding position in normal males. Neurourol Urodyn 1999; 18:553-7.

10. Eryildirim B, Tarhen F, Kuyumcuoglu U, et al. Position related changes in uroflowmetric parameters in healthy young men. Neurourol Urodyn 2006;25:249-51.

11. Choudhury S, Agarwal MM, Mandal AK, et al. Which Voiding Position Is Associated With Lowest Flow Rates in Healthy Adult Men? Role of Natural Voiding Position. Neurourol Urodyn 2010;29:413-7.

12. Devreese AM, Nuyens G, Staes F, et al. Do posture and straining influence urinary-flow parameters in normal woman? Neurourol Urodyn 2000;19:3-8.

13. Gupta NP, Kumar A, Kumar R. Does position affect uroflowmetry parameters in women? Urol Int 2008:80:37-40

14. Moore KH, Richmond DH, Sutherst JR, et al. Crouching over the toilet seat: Prevalence among British gynaecological out patients and its effect upon micturition. Br I Obstet Gynaecol 1991;98:569-72.
15. Chou EC, Yang PY, Hsueh WH, et al. Urinating in the standing position: a feasible alternative for elderly women with knee osteoarthritis. J Urol 2011;186:949-53.

16. Unsal A, Cimentepe E. Effect of voiding position on uroflowmetric parameters and post-void residual urine volume in patients with benign prostatic hyperplasia. Scand I Urol Nephrol 2004;38:240-2.

17. Aghamir SM, Mohseni M, Arasteh S. The effect of voiding position on uroflowmetry findings of healthy men and patients with benign prostatic hyperplasia. Urol J 2005;2:216-21.

18. Amjadi M, Madaen SK, Pour-Moazen H. Uroflowmetry findings in patients with bladder outlet obstruction symptoms in standing and crouching positions. Urol J 2006;3:349-53.

19. El-Bahnasawy MS, Fadl FA. Uroflowmetric differences between standing and sitting positions for men used to void in the sitting position. Urology 2008;71:465-8.

Correspondence: Dr. Gokhan Koc, Tepecik Teaching and Research Hospital Urology Department, Yenisehir, Izmir, 35121, Turkey; fax:+902324330756; gokfekoc@gmail.com 